Psychopharmacology 52, 97-102 (1977)

\title{
Pargyline-Induced Increases in Sensitivity to the Effects of Drugs on Operant Behavior in Pigeons
}

\author{
JOHN M. CARNEY* \\ Department of Pharmacology, The University of Michigan Medical School, Ann Arbor, Michigan 48004, U.S.A.
}

Abstract. Pigeons responded under a multiple fixedinterval 5-min, 30-response fixed-ratio schedule of food reinforcement. Acute pargyline doses between 10.0 and $50.0 \mathrm{mg} / \mathrm{kg}$ (i.m.), given immediately prior to the session, decreased responding. Daily administration of $50 \mathrm{mg} / \mathrm{kg}$ pargyline ( $24 \mathrm{mg} / \mathrm{kg}$, every $12 \mathrm{~h}$ ) initially decreased responding. Tolerance developed so that after 4 days of daily pargyline, responding had returned to control values. Chronic pargyline resulted in an enhanced sensitivity to the effects of $d$-amphetamine, ephedrine, tyramine, and morphine on schedule-controlled responding. Both $d$-amphetamine and pentobarbital increased fixed-interval responding at relatively low doses, while higher doses decreased responding. Daily pargyline resulted in an increased sensitivity to both the increases and decreases in response rates produced by $d$-amphetamine. In contrast, sensitivity to pentobarbital was not changed after daily pargyline. Ephedrine, tyramine, and morphine only decreased fixed-interval responding. Chronic pargyline resulted in an increased sensitivity to the response-rate decreasing effects of ephedrine, tyramine, and morphine. In addition to the increased sensitivity of fixed-interval responding to the effects of tyramine, the dose-effect curve for fixed-ratio responding was also a shifted to the left. Daily pargyline did not result in changes in sensitivity of fixedratio responding to the effects of the other drugs tested.

Key words: Operant behavior - Tolerance - Pargyline - Pigeons - Sympathomimetics - Pentobarbital - Morphine.

* NIH Predoctoral Trainee in Pharmacology

Present address and address for offprint requests: Department of Pharmacology, Medical College of Virginia, Richmond, Virginia 23298, U.S.A.
Indirectly-acting sympathomimetics are thought act by releasing biogenic amines from nerve terminals (Burn and Rand, 1958; Trendelenburg, 1963). In the peripheral nervous system tyramine, $d$-amphetamine, and other indirectly-acting sympathomimetics produce their effects on heart rate, blood pressure, bronchial smooth muscle tone, etc. by releasing catecholamines stored within adrenergic nerves and related tissues (Potter and Axelrod, 1963; Trendelenburg, 1963; Smith, 1966).

In addition to their effects on the peripheral nervous system, amphetamine and other indirectlyacting sympathomimetics produce increases in spontaneous locomotor activity in rodents (Smith, 1963; Van Rossum and Hurkmans, 1964; Costa et al., 1972) and stimulate, suppress, and reinforce operant responding (McMillan, 1968a,b; Pickens and Thompson, 1968; Tilson and Sparber, 1972; Goldberg, 1973). It has been proposed that the stimulation of locomotor activity is at least in part due to the drug-induced release of catecholamines in the brain (Van Rossum and Hurkmans, 1964; Carlsson, 1970). In support of this hypothesis, it has recently been demonstrated that ventricular perfusion of the cat brain with $d$-amphetamine will cause a release of radiolabeled dopamine into the lateral ventricle (Chiueh and Moore, 1975). In addition, drugs that inhibit the conversion of tyrosine to catecholamines result in a decreased sensitivity to psychomotor stimulants (Weissman et al., 1966; Dominic and Moore, 1969). Inhibition of monoamine oxidase (MAO) with pargyline resulted in increased sensitivity to the locomotor stimulant effects of a series of N-ethyl amphetamines (Tessel et al., 1975), consistent with the hypothesis of a druginduced intraneuronal release of catecholamines in the brain which produces the locomotor stimulation. Narcotic analgesics also produce dose-related increases in spontaneous locomotor activity; pretreatment with MAO inhibitors resulted in increased 
sensitivity and amine depletion resulted in decreased sensitivity to the locomotor stimulant effects of narcotics (Hollinger, 1969; Carrol and Sharp, 1972; Villarreal et al., 1973), suggesting that the effect of narcotics may also be due to the release of catecholamines in the brain central nervous system.

The present study was conducted to determine if the sensitivity of operant responding to the effects of morphine and a series of sympathomimetic amines could be enhanced by daily injections of the MAO inhibitor pargyline. Aprison and Ferster (1961) previously demonstrated an enhanced sensitivity of pigeons to the effects of 5-hydroxy-tryptophan on operant behavior after MAO inhibition by iproniazid. In the present study, pargyline-induced increases in sensitivity were determined by comparing dose-effect curves before and during daily pargyline. Pentobarbital doses were also tested, since it, like amphetamine, produced increases in food-reinforced responding under a multiple FI-FR schedule (Rutledge and Kelleher, 1965).

\section{METHODS}

Subjects. Subjects were six male pigeons (three White Carneaux and three Silver Kings), weighing between 400 and $600 \mathrm{~g}$ when allowed free access to food and water. All birds had prior histories of operant responding. None had received any drugs for at least 3 months prior to the start of the study. Birds were deprived of food until they reached $80 \%$ of their free feeding weights; they were maintained at this level by post-session supplemental feeding.

Apparatus. The three experimental chambers were closely similar to those described by Ferster and Skinner (1957). White noise was continuously present in each chamber to help mask extraneous noise. Chambers were ventilated by exhaust fans. An acrylic response key ( $1.9 \mathrm{~cm}$ diameter) could be transilluminated by blue or red $7 \mathrm{w}$ light bulbs and was operated by a force equivalent to a weight of about $15.0 \mathrm{~g}$. Four seconds access to mixed grain served to maintain responding and it was made available through a rectangular opening in the front wall of the chamber below the response key. Electromechanical switching, timing, and counting devices were used to control the experiment.

Procedure. Pigeons were trained to respond by reinforcing successive approximations of the key-peck response. Under the terminal sichedule conditions food was presented following the first response after $5 \mathrm{~min}$ in the presence of a red light (fixed-interval 5-min; FI 5), or after the thirthieth response in the presence of a blue key light (fixed-ratio 30-response; FR 30). The key lights were extinguished and the food hopper was illuminated by a white light during food presentation. If a bird did not respond within $60 \mathrm{~s}$ after each FI 5 had elapsed, no food was delivered and the schedule advanced to the next FR 30 component. Similarly, if 30 responses were not emitted within $60 \mathrm{~s}$ in each FR 30 component, no food was delivered and the schedule was switched to the next FI 5 component. Each session consisted of ten FI 5 and ten FR 30 components which alternated throughout the session. Under these schedule conditions, the session length was approximately $60 \mathrm{~min}$. Each bird was run for a minimum of 30 days before drug testing. Sessions were conducted daily. Stability in all cases was defined as no consistent upward or downward trend in response rate or quarter-life (QL) across sessions.
Dose-Effect Curves. Test doses of morphine, pentobarbital, $d$-amphetamine, tyramine, and pargyline were administered immediately before the start of the session. Drugs were dissolved in saline and injected into the breast muscle of the bird. Drugs were tested no more frequently than every fifth day; saline was injected on intervening days. Doses were tested in an increasing dose sequence.

In the second phase of the experiment, pargyline was administered every $12 \mathrm{~h}$, at a dose of $25 \mathrm{mg} / \mathrm{kg}$. One of the two daily injections was given immediately before the session. After responding had stabilized under the chronic pargyline regimen, morphine, $d$-amphetamine, tyramine, and pentobarbital dose-effect curves were re-determined. Drugs were tested every fifth day; on test days both pargyline and the test dose were injected before the session.

Data Analysis. Response rates were calculated in responses/s for FI and FR components. QL, a measure of response distribution within FI components, was computed on the basis of average response rates innsuccessive 30 -s segments of each FI component according to the method of Gollub (1964). This statistic represents the average amount of time, expressed as a percentage of the total FI time, required for the emission of one-fourth of the total responses in each FI.

Drugs. Morphine sulfate, $d$-amphetamine sulfate, ephedrine sulfate, tyramine hydrochloride (grade B, CalBiochem), pargyline hydrochloride (Abbott Labs), and sodium pentobarbital were dissolved in $0.9 \%$ saline. Doses refer to the salt. Drug concentrations were adjusted so that each bird received $1.0 \mathrm{ml}$ per $\mathrm{kg}$ body weight. Drugs were injected into the breast muscle of the bird.

\section{RESULTS}

Control performance under the multiple FI 5, FR 30 schedule was similar to that previously reported for this schedule of reinforcement (e.g., Ferster and Skinner, 1957; Heifetz and McMillan, 1971). The mean response rate was 0.51 responses/s in FI and 2.05 in FR components (Fig.1). FI responding showed the characteristic positively accelerated pattern of responding, indicated by a QL of 0.51 (Fig. 1). FR 30 responding was characterized by a brief initial pause, followed by a high and relatively constant rate of responding. There was no apparent difference in either control responding or in the sensitivity to drugs for the two breeds of pigeons used.

Pargyline produced dose-related decreases in all measures of the pattern and rate of responding (Fig. 1). FI responding appeared somewhat more sensitive than FR behavior to pargyline in that a $20 \mathrm{mg} / \mathrm{kg}$ dose decreased FI rates to about $50 \%$ of control and did not change FR rates. At $50 \mathrm{mg} / \mathrm{kg}$, FI rates were at or close to zero, while FR rates were not as completely suppressed. One of the six birds failed to recover from the $50 \mathrm{mg} / \mathrm{kg}$ dose and died 3 days later. The other five birds recovered to control values within a few days.

Daily injections of pargyline ( $25 \mathrm{mg} / \mathrm{kg}$, every $12 \mathrm{~h})$ resulted in the development of tolerance to the effects of pargyline (Fig. 2). Pargyline initially decreased FI and FR response rates and QL value. Similar to the 


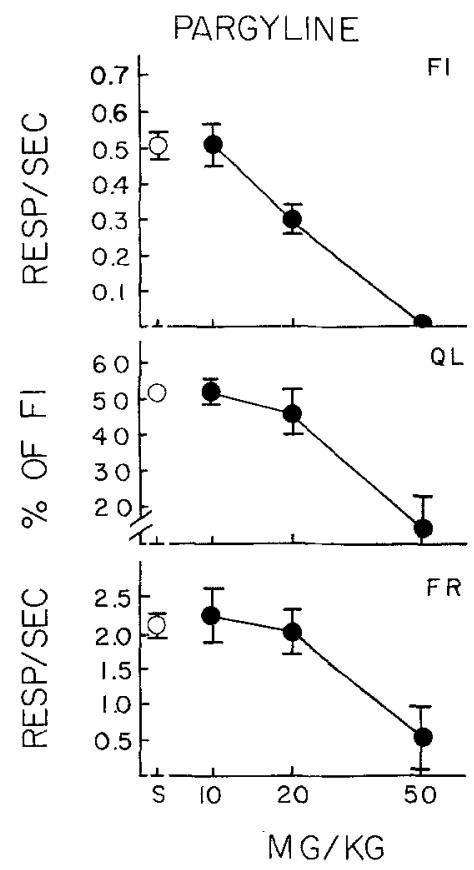

Fig. 1. Effects of pre-session pargyline (e) and saline (O) on $F I$ and $F R$ response rates and on fixed-interval quarter-life $(Q L)$ values. Response rates are expressed in responses per second and $Q L$ as a percentage of the 5-min $F I$. Intramuscular injections were given immediately before the start of the session. Each point is the mean ( \pm S.E.) of six observations per dose of pargyline and 12 observations for saline. See Methods for further details of the schedule and injection protocol

data described above, FI responding was more sensitive than FR to the effects of $25 \mathrm{mg} / \mathrm{kg}$ pargyline. Responding recovered to control rates within the first 4 days of chronic pargyline and remained at this level throughout the remainder of the study.

Amphetamine produced both increases and decreases in FI response rates and only decreases in FR rates (Fig. 3). Analysis of the amphetamine-induced changes in responding during individual 30 -s segments of the FI indicated that the lowest rates were increased and higher rates were increased less or decreased (Fig. 4). Daily pargyline resulted in an increased sensitivity to the effects of amphetamine on FI responding; the dose-effect curve for FR responding was not affected. The pargyline-induced increase in sensitivity to amphetamine was also seen in the change in the effects of amphetamine on responding in individual segments of the FI (Fig. 4). A dose that initially did not affect FI responding $(0.1 \mathrm{mg} / \mathrm{kg})$ produced effects equivalent to $0.32 \mathrm{mg} / \mathrm{kg}$ after chronic pargyline (Figs. 3 and 4).

In contrast to $d$-amphetamine, doses of ephedrine and tyramine produced only decreases in average rates of FI, responding and decreased FR rates (Fig. 3). These drugs produced the greatest decreases in the
PARGYLINE $25 \mathrm{mg} / \mathrm{kg}$ (q.12 hrs.)

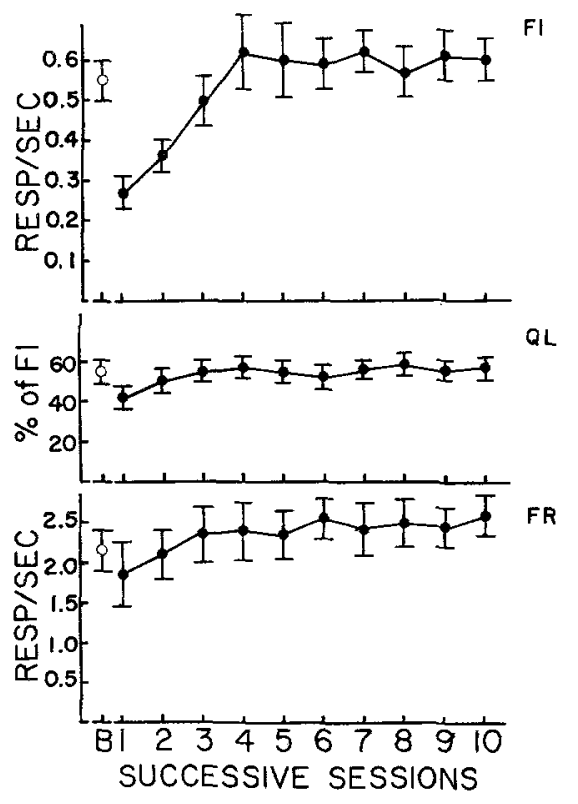

Fig. 2. Changes in sensitivity to the effect of pargyline produced by chronic pargyline injections $(25 \mathrm{mg} / \mathrm{kg}$, every $12 \mathrm{~h}$ ). Baseline values $(O)$ represent the mean $( \pm S . E$.) for the last 2 days in each of five birds $(n=10)$. Each point during chronic pargyline $(\bullet)$ is the mean ( \pm S.E.) for one observation in each of five birds $(n=5)$. Pargyline was injected immediately before the session and 12-h after the pre-session injection; injections were given 7 days a week

highest rates of responding in local FI segments (Fig. 4). At the lower response rates the drugs produced less of a decrease or slight increases in responding (Fig.4). Daily pargyline injection resulted in a shift to the left of the tyramine and ephedrine dose-effect curves for FI (3- and 10-fold, respectively) and a similar increase in the effectiveness of these drugs on responding in local segments of the FI (Fig.4). In contrast to the other drugs, the tyramine dose-effect curve for FR responding was shifted to the left about 3-fold after chronic pargyline.

Pentobarbital produced both increases and decreases in FI response rates; FR rates were decreased at doses that also decreased FI rates. Relatively low rates of responding in local segments of the FI were increased more than the relatively high FI rates. In contrast to the other drugs tested, chronic pargyline did not result in any change in sensitivity to the effects of pentobarbital on responding.

Morphine produced dose-related decreases in FI and $\mathrm{FR}$ responding. After chronic pargyline the doseeffect curve for FI was shifted slightly to the left. The increase in morphine sensitivity after pargyline was reflected in changes in the effectiveness of morphine on responding in local segments of the FI. 


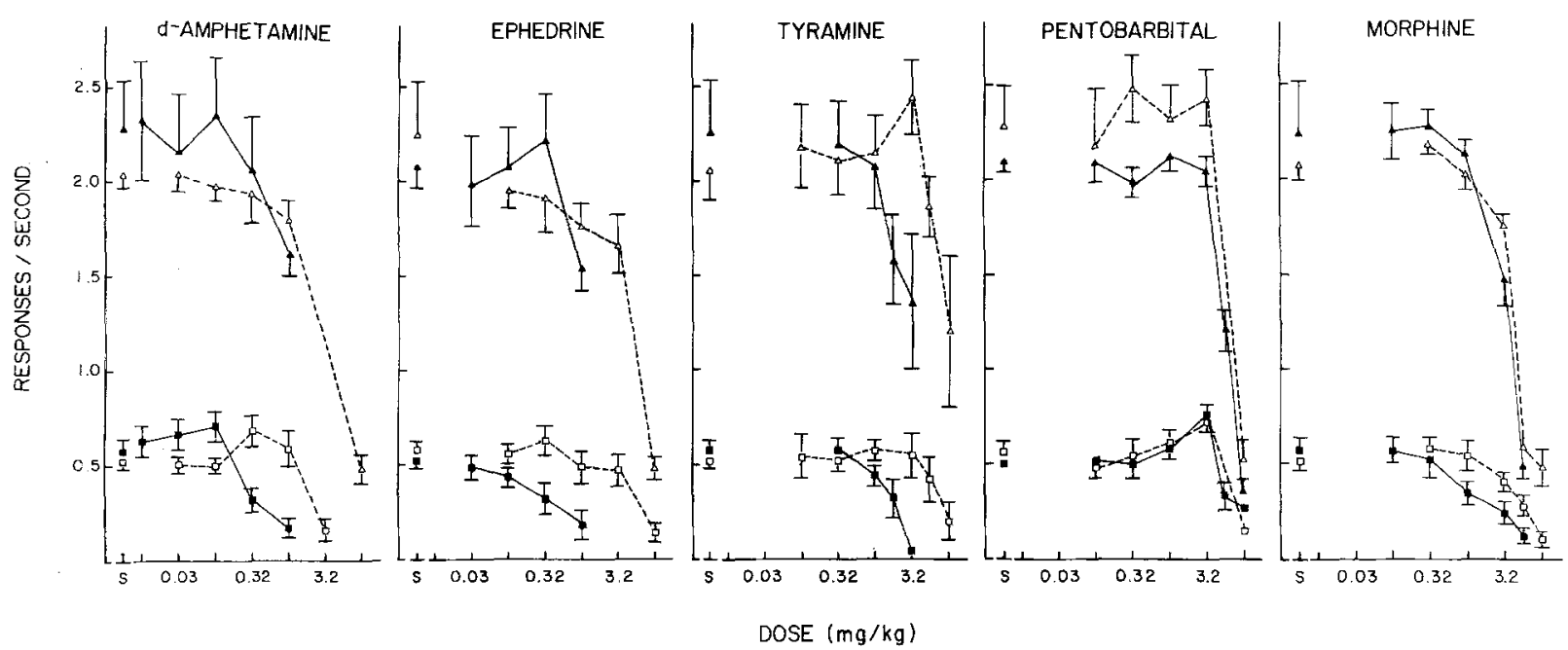

Fig. 3. Pargyline-induced changes in sensitivity to the effects of $d$-amphetamine, ephedrine, tyramine, pentobarbital and morphine on $\mathrm{FI}(\triangle, \Delta)$ and FR $(\mathrm{O}, \bullet)$ responding. Open symbols represent the effects of the different drugs $(O)$ and saline $(S)$ on FI and FR responding prior to chronic pargyline. Solid symbols represent the effects of saline and the drugs on responding after more than 14 days of daily pargyline $(25 \mathrm{mg} / \mathrm{kg}$, every $12 \mathrm{~h})$. Each point is the mean ( \pm S.E.) of 5 observations per dose; drugs were given immediately before the start of the session

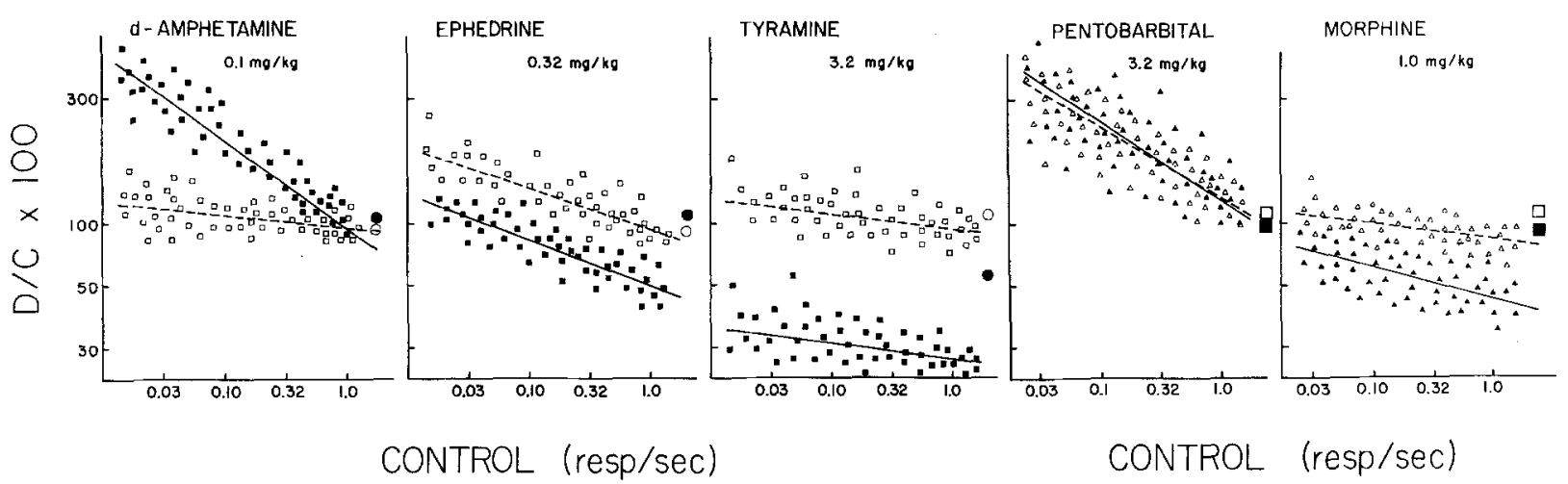

Fig. 4. Changes in the effects of $d$-amphetamine, ephedrine, tyramine, pentobarbital, and tyramine on responding in $30 \mathrm{~s}$ segments of the FI (small symbols) and on FR rates (larger symbols). Open symbols represents the effects of the drugs on responding prior to chronic pargyline and solid symbols represent drug induced changes in responding are plottedd as the ratio of the rate of responding after drug divided by the control rate (D/C) time 100 vs. the control average response rate for that $30 \mathrm{~s}$ segment of the FI. Least squares regression line, for the FI date only, are plotted for each drug both before chronic pargyline (----) and during chronic pargyline $(-)$. For reference, a no-effect line would be paralleled to the $x$ axis at the $100-D / C$. Drugs were given immediately before the session

\section{DISCUSSION}

Both pentobarbital and $d$-amphetamine produced increases and decreases in FI response rates. Morphine, ephedrine, and tyramine produced only decreases in the average rate of FI responding. All the drugs produced only decreases in FR response rates. The sensitivity of FI responding was increased after daily pargyline $(25 \mathrm{mg} / \mathrm{kg}$ every $12 \mathrm{~h})$ for all the drugs except pentobarbital.

As with many other centrally-active drugs, a range of acute pargyline doses produced decreases in FI and FR response rates and QL. FI responding appeared to be more sensitive to pargyline at the 20,25 , and
$50 \mathrm{mg} / \mathrm{kg}$ doses. Chronic administration of pargyline at $25 \mathrm{mg} / \mathrm{kg}$ (i.m., every $12 \mathrm{~h}$ ) resulted in an initial decrease in both FI and FR response rates. Tolerance developed to pargyline, evidenced by a progressive recovery of responding across days. In addition to pargyline, tolerance has been reported to develop to the behavioral effects of methadone and morphine (Heifetz and McMillan, 1971), delta-9-tetrahydrocannabinol (McMillan et al., 1971), $d$-amphetamine (Schuster et al., 1966; Fischman and Schuster, 1975), sedative hypnotics, and ethyl alcohol (Kalant et al, 1971). The data for pargyline demonstrate that the phenomenon of tolerance to the behavioral effects of a drug can be extended to include such compounds 
as the monoamine oxidase inhibitors, of which pargyline is one example.

Morphine sensitivity was increased by about 3-fold for FI responding after daily pargyline. Increases in sensitivity to morphine as a result of pargyline or iproniazid pretreatment have been reported for stimulation of spontaneous motor activity in rodents (Hollinger, 1967; Carroll and Sharp, 1972; Villarreal et al., 1973) and for morphine-induced analgesia (Yeh and Mitchell, 1971). Morphine results in increases in catecholamine turnover (Smith et al., 1972). Pretreatments with drugs that decrease catecholamine content by interfering with synthesis or storage reduce the stimulant effects of morphine on locomotor activity (Hollinger, 1969; Villareal et al., 1973). These and other data have led to the hypothesis that the effects of morphine are mediated in part by its effects on catecholamines in the central nervous system. The increased sensitivity to morphine effects on FI responding after the chronic administration of pargyline are consistent with the hypothesis that the effects of morphine on operant responding are mediated by its effects on brain monoamines. Since both catecholamines and indoleamines are metabolized via monoamine oxidase, it is not possible to determine which of these amines are responsible for the effects of morphine on operant behavior.

In addition to morphine, sensitivity to $d$-amphetamine was increased after chronic pargyline for both the drug-induced increases and decreases in responding. Amphetamine produced increases in FI responding at 0.32 and $1.0 \mathrm{mg} / \mathrm{kg}$. Lower doses had no effect on responding and higher doses decreased FI rates. Similar $d$-amphetamine-induced increases and decreases in FI responding have been reported for pigeons (McMillan, 1968a) and monkeys (McMillan, 1968 b; McKearney, 1974; Herling et al., 1975). After chronic pargyline, the amphetamine dose-effect curves for FI and FR responding were shifted to the left. Similar increases in amphetamine sensitivity after pretreatment with monoamine oxidase inhibitors such as pargyline and iproniazid have been reported for stimulation of spontaneous motor activity in mice and stimulation of guinea pig atrial rate (Smith, 1965, 1966). The other sympathomimetic amines only decreased average FI rates. McMillan (1968a) reported that ephedrine increased FI rates at doses between 1.0 and $3.0 \mathrm{mg} / \mathrm{kg}$. In the present study, ephedrine only decreased FI responding at doses between 0.1 and $10.0 \mathrm{mg} / \mathrm{kg}$. However, some increases in the relatively low rates of responding in local segments of the FI were observed for both tyramine and ephedrine and to this extent the data are similar to that of McMillan (1968a).
Chronic pargyline enhanced the sensitivity to the effects of the tyramine on both local FI rates and overall FI and FR response rates. Tyramine is a good substrate for MAO and some of the shift to the left for tyramine, which was 3 times greater than any of the other drugs, may have been due to an inhibition of tyramine metabolism. In addition to the possible increase in functional dose of tyramine due to inhibition of metabolism, tyramine is an indirectly-acting amine and some of the enhanced sensitivity may be due to an inhibition of biogenic amine metabolism. In the peripheral nervous system, tyramine acts by releasing endogenous norepinephrine within adrenergic nerves (Smith, 1966), and the effects of tyramine are enhanced after pargyline (Antanaccio and Smith, 1969). On the other hand, ephedrine has an alphamethyl group and, consequently, is less likely to serve as a substrate for MAO. Thus, the shift to the left of the ephedrine dose-effect curve is more likely to be the result of the inhibition of biogenic amine metabolism.

The data for pentobarbital demonstrate that chronic pargyline does not necessarily result in an increased sensitivity to the behavioral effects of all drugs. Pentobarbital increased FI responding at $3.2 \mathrm{mg} / \mathrm{kg}$ and decreased rates at $10 \mathrm{mg} / \mathrm{kg}$. Chronic pargyline did not result in any changes in the pentobarbital dose-effect curves.

Acknowledgements. This research was supported in part by USPHS Grants DA-00154 and GM-00198.

\section{REFERENCES}

Antonaccio, M. J., Smith, C. B.: Effects of chronic pretreatment with pargyline upon responses of the atrial pacemaker and of left atrial strips of guinea pigs to tyramine, mephentermine, $d$-amphetamine and adrenergic nerve stimulation. J. Pharmacol. exp. Ther. 170, $97-107$ (1969)

Aprison, M. H., Ferster, C. B.: Neurochemical correlates of behavior. II: Correlation of brain monoamine oxidase activity with behavioral changes after iproniazid and 5-hydroxy-tryptophan administration. J. Neurochem. 6, 350-357 (1961)

Burn, J. H., Rand, M. J. : The actions of sympathomimetic amines in animals treated with reserpine. I. Physiol. (Lond.) 144, $314-346(1958)$

Carlsson, A.: Amphetamine and brain catecholamines. In: Amphetamines and related compounds, E. Costa and S. Garattini, eds., pp. 289-300. New York: Raven Press 1970

Carroll, B. J., Sharp, P. T.: Monoamine mediation of the morphineinduced activation of mice. Brit. J. Pharmacol. 46, 124-139 (1972)

Chiueh, C. C., Moore, K. E.: $d$-Amphetamine-induced release of "newely synthesized" and "stored" dopamine from the caudate nucleus in vivo. J. Pharmacol. exp. Ther. 192, 642-653 (1975)

Costa, E., Groppetti, A., Naimzada, M. K.: Effects of amphetamine on the turnover rate of brain catecholamines and motor activity. Brit. J. Pharmacol. 44, 742-751 (1972)

Dominic, J. A., Moore, K. E.: Supersensitivity to the central stimulant actions of adrenergic drugs following discontinuation of a 
chronic diet of 2-methyltyrosine. Psychopharmacologia (Berl.) 15, 196-201 (1969)

Ferster, C. B., Skinner, B. F.: Schedules of reinforcement. New York: Appleton-Century-Crofts 1957

Fischman, M. W., Schuster, C. R.: Behavioral, biochemical and morphological effects of methamphetamine in the rhesus monkey. In: Behavioral toxicology, B. Weiss and V. G. Laties, eds. New York: Plenum Press 1975

Goldberg, S. R.: Comparable behavior maintained under fixedratio and second order schedules of food presentation, cocaine injection, or $d$-amphetamine injection in the squirrel monkey. J. Pharmacol. exp. Ther. 186, 18-30 (1973)

Gollub, L. R.: The relations among measures of performance of fixed-interval schedules. J. exp. Anal. Behav. 7, 337-343 (1964)

Heifetiz, S. A., McMillan, D. E.: Development of behavioral tolerance to morphine and methadone using the schedule-controlled behavior of the pigeon. Psychopharmacologia (Berl.) 19, 40-52 (1971)

Herling, S., Downs, D. A., Woods, J. H.: Rate-dependent effects of drugs on food- and cocaine-reinforced lever-press responding in rhesus monkeys. Fed. Proc. 34, 765 (1975)

Hollinger, M.: Effect of reserpine, alpha-methyl-p-tyrosine, p-chlorophenyl-alanine and pargyline on levorphanol-induced running activity in mice. Arch. int. Pharmacodyn. 179, 419-424 (1969)

Holtzman, S. R., Jewett, R. E.: The role of brain norepinephrine in the anorexic effects of dextroamphetamine and monoamine oxidase inhibitors in the rat. Psychopharmacologia (Berl.) 22, $151-161$ (1971)

Kalant, H., LeBlanc, A. E., Gibbins, R. J.: Tolerance to, and dependence on, some non-opiate psychotropic drugs. Pharmacol. Rev. 23, 135-191 (1971)

McMillan, D. E.: The effects of sympathomimetic amines on schedule-controlled behavior in pigeons. J. Pharmacol. exp. Ther. 160, 315-325 (1968 a)

McMillan, D. E.: Some interactions between sympathomimetic amines and amine-depleting agents on the schedule-controlled behavior of the pigeon and the squirrel monkey. J. Pharmacol. exp. Ther. 163, 172-187 (1968 b)

McMillan, D. E., Dewey, W. L., Harris, L. S.: Characteristics of tetrahydrocannabinol tolerance. Ann. N.Y. Acad. Sci. 191, 83-99(1971)

McKearney, J. W.: Effects of $d$-amphetamine, morphine and chlorpromazine on responding under fixed-interval schedules of food presentation and selective shock presentation. J. Pharmacol. exp. Ther. 190, 141-153 (1974)

Pickens, R., Thompson, T.: Cocaine-reinforced behavior in rats: Effects of reinforcement magnitude and fixed-ratio size. J. Pharmacol. exp. Ther. 161, 122-129 (1968)

Potter, L. T., Axelrod, J.: Studies on the storage of norepinephrine and the effects of drugs. J. Pharmacol. exp. Ther. 140, 199-206 (1963)
Rutledge, C. O., Kelleher, R. T.: Interactions between the effects of methamphetamine and pentobarbital on operant behavior in the pigeon. Psychopharmacologia (Berl.) 7, 400-408 (1965)

Schuster, C. R., Dockens, W. S., Woods, J. H. : Behavioral variable affecting the development of amphetamine tolerance. Psychopharmacologia (Berl.) 9, 170-182 (1966)

Smith, C. B.: Enhancement by reserpine and alpha-methyl-dopa of the effects of $d$-amphetamine upon the locomotor activity of mice. J. Pharmacol. exp. Ther. 142, 343-350 (1963)

Smith, C. B.: Effects of $d$-amphetamine upon brain amine content and locomotor activity of mice. J. Pharmacol. exp. Ther. 147, 96-102 (1965)

Smith, C. B.: The role of monoamine oxidase in the intraneuronal metabolism of norepinephrine released by sympathomimetic amines or by adrenergic nerve stimulation. J. Pharmacol. exp. Ther. 151, 207-220 (1966)

Smith, C. B., Sheldon, M. I., Bednarczyk, J. H., Villarreal, J. E.: Morphine-induced increases in the incorporation of 14C-tyrosine into 14C-dopamine and 14C-norepinephrine in the mouse brain: Antagonism by naloxone and tolerance. J. Pharmacol. exp. Ther. 180, 547-557 (1972)

Tessel, R. E., Woods, J. H., Counsel, R. E., Lu, R. M. : Structureactivity relationships between meta-substituted $\mathrm{N}$-ethyl amphetamines and locomotor activity in mice. J. Pharmacol. exp. Ther. 192, 310-318 (1975)

Tilson, H. A., Sparber, S. B.: Studies on the concurrent behavioral and neurochemical effects of psychoactive drugs using the pushpull cannula. J. Pharmacol. exp. Ther. 181, 387-398 (1972)

Trendelenberg, U., Gomez Alonso de la Sierra, B., Muskus, A.: Modification by reserpine of the response of the atrial pacemaker to sympathomimetic amines. J. Pharmacol. exp. Ther. 141, $301-309$ (1963)

Van Rossum, J. M, Hurkmans, J. A., Th. M.: Mechanism of action of psychomotor stimulant drugs: Significance of dopamine in locomotor stimulant actions. Int. J. Neuropharmacol. 3, $227-239$ (1964)

Villarreal, J. E., Guzman, M., Smith, C. B.: Comparison of $d$ amphetamine and morphine upon locomotor activity of mice treated with drugs which alter brain catecholamine content. J. Pharmacol. exp. Ther. 187, 1 - 7 (1973)

Weissman, A., Koe, B. K., Tenen, S. S.: Antiamphetamine effects following inhibition of tyrosine hydroxylase. J. Pharmacol. exp. Ther. 151, 339-352 (1966)

Yeh, S. Y., Mitchell, C. L.: Potentiation and reduction of the analgesia of morphine in the rat by pargyline. J. Pharmacol. exp. Ther. 179, 642-651 (1971)

Received June 2, 1976; Final Version November 9, 1976 